\title{
Study on the urban residential public space planning strategies based on the improvement of immune level in severe cold area
}

\author{
Cunyan JIANG, School of Architecture, Harbin Institute of Technology; Key Laboratory of Cold Region \\ Urban and Rural Human Settlement Environment Science and Technology, Ministry of Industry and \\ Information Technology, China \\ Qing YUAN, School of Architecture, Harbin Institute of Technology; Key Laboratory of Cold Region \\ Urban and Rural Human Settlement Environment Science and Technology, Ministry of Industry and \\ Information Technology, China
}

\begin{abstract}
Active urban residential public space helps human body maintain normal immune level. Based on some qualitative research and in situ measurement methods, this paper 1) Analysis cold climate's negative effects on people's immune level; 2) Develop some empirical research through field survey on climate measurement and structured interview; 3) Advance some planning strategies on urban residential public space based on immune level improvement. The research results can optimize the relevant planning indicators and design principles, promote the formation of a positive urban residential public space in severe cold area, and provide empirical basis for the urban material space planning from the perspective of immune level improvement in severe cold area.
\end{abstract}

\section{Keywords}

Residential public space, Immune Level, Planning Strategies, Severe cold areas

\section{Introduction}

The importance of body immune level in the treatment of novel coronavirus pneumonia caused by COVID-2019 has been confirmed(Zhang, W.H. 2020). Patients with chronic diseases such as cardiovascular, cerebrovascular, hypertension and diabetes are more susceptible to infection, and the immune system dysfunction and overreaction of immune cells are obvious(Zimmer, K. 2020). At the same time, due to the shortage of medical resources, some patients with mild or even asymptomatic infection with relatively perfect immune system were isolated at home without treatment and finally recovered(Lang, T.Y. 2020). Therefore, normal immune level plays an important role in dealing with acute infectious diseases and long-term health management(Zhang, X.C. 1985). Active urban residential public space environment helps human body maintain normal immune level through promoting physical activity and helping keep healthy mood, which is confirmed by large quantities of related studies(Maas, J., Verheij, R.A. 2007 \& Oh, B. 2017).

However, for the city located in the high latitude and cold area, on the one hand, the cold climate will affect the human body immune level. For example, low temperature in winter increases the metabolic oxygen demand and decreases the activity of immune cells, so as to reduce the ability of the body to 
resist pathogenic microorganisms(Yin, X.H.etc..1996 \& Du, C.Q.2018). At the same time, many viral activities that cause infectious diseases have been proved to be closely related to the climate, and the human immune system is more vulnerable to viruses in winter. For example, influenza virus, H1N1 virus, SARS virus, etc. will lose their activity quickly when they encounter high temperature above $30^{\circ} \mathrm{C}$ (Wang, M. etc..2020), however the lower temperature in winter makes the virus more stable and stay in the air for a longer time after leaving the human body. Therefore, some experts conclude that it is not unusual that the mortality rate in severe cold areas is relatively higher in warm areas in the epidemic(Zhong, N.S.2020).

On the other hand, the severe cold climate reduces the effectiveness of urban built-up environment on human immunity. The main performance is that the accessibility of urban built-up environment, safety and comfort, and landscape pleasure bring negative effects on outdoor physical activity participation and emotional and psychological cognition of residents. First of all, icy road, low temperature and cold wind directly reduce the time and frequency of residents' outdoor physical activity in severe cold areas(Leng, $\mathrm{H}$. etc..2017). Secondly, the increase of buildings shadow area in winter leads to insufficient sunshine, and the intake of vitamin D is less, which is not conducive to the absorption of calcium ions(Shi, X.S.etc.. 2013). In addition, the original function of improving the ecological system of the built environment in winter is affected, and its function of absorbing dust and killing bacteria is greatly reduced, which also has a significant impact on human immune level(Wang, Z.G.2003).

The effects of climate environment on immune level in severe cold areas can be summarized as Figure 1 , which can be divided in direct and indirect aspects. Related research on the relationship between residential public space elements and immune level in severe cold areas is rare in literature. This study took Harbin, a typical Chinese winter city, as its research subject. The purpose of the study are (1) Develop a field survey on people's self test on immune level condition, activity rules and satisfaction towards residential public space during the outbreak of COVID-2019; (2) Discussion the relationship between related factors; and (3) Advance some planning implication to improve residents' immune level in severe cold areas.

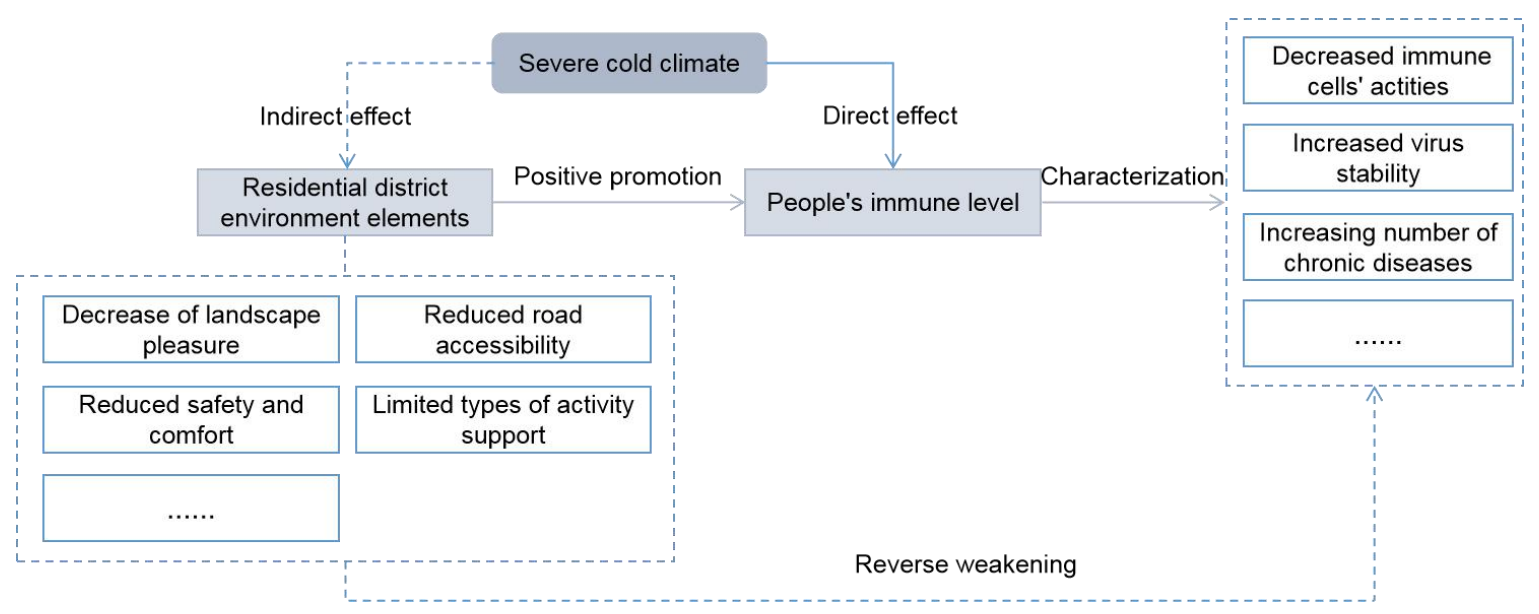

Figure 1: Direct and indirect effects of climate environment on immune level in severe cold areas

\section{Methods}

\subsection{Study Site}

Harbin is located at $45^{\circ}$ latitude $\mathrm{N}$ and $128^{\circ}$ longitude $\mathrm{E}$ and is known as a typical winter city in the northeast of China. Harbin is the capital city of Heilongjiang Province, and also the transportation, political, economic, cultural and financial center of northeastern China, with a total population of 10.76 
million at the end of 2019. The city of Harbin encompasses approximately $53100 \mathrm{~km}^{2}$, with the GDP of 524.9 billion. A location map of Harbin is shown in Figure 2. Harbin belongs to the temperate continental monsoon climate zone, the annual mean temperature of which was $3.6^{\circ} \mathrm{C}$. Usually, summer is from June to August, and winter is from November to March. There is always strong wind with frequent snowfall in winter, which has obvious influence on people's normal life.

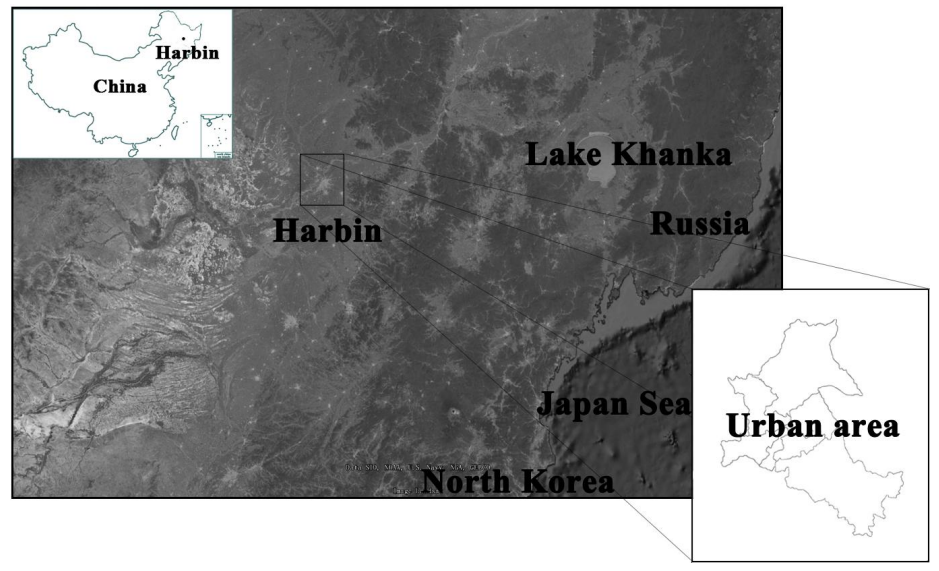

Figure 2: The Location Map of Harbin

\subsection{Field survey methods}

\subsubsection{Studies areas}

To measure the degree of residential public space influence on people's immune level, two typical residential public space with different designs were chosen as field survey sites in Harbin. the One relatively new residential district is with a perfect facilities and pleasant landscape, the other one is a relatively old residential district lacking of facilities and landscape. The environmental construction conditions of the two residential districts is shown in Figure 3 . The field survey were conducted simultaneously in the two selected areas.
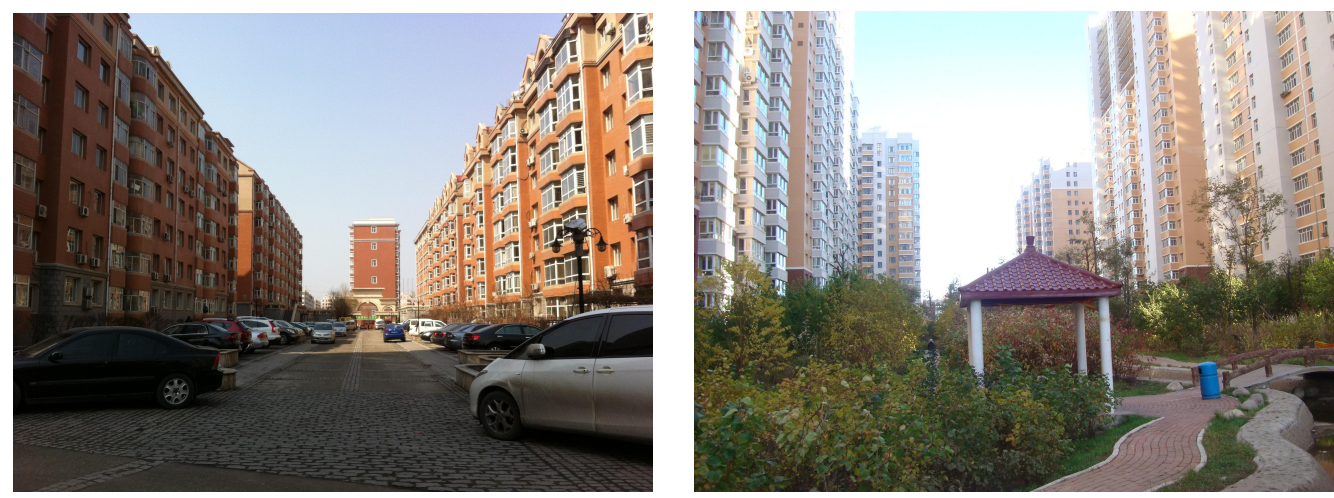

Figure 3: Residents' environmental construction conditions of the two residential districts

\subsubsection{Structured interview}

This study adopted structured interviews in the two selected areas in June, in which the outbreak of COVID-2019 is well controlled. Each interview took approximately 5 mins (Thorsson, C.W. 2007). The interview comprised three main topics. A total of 324 people participated in the interview process (198 in old residential district and 126 in new residential district) within 9 days. Approximately, 20-40 interviews were conducted daily in the two areas. $71.5 \%$ of the participants were between 20 and 70 years of age. The ratio of male to female is about $4 / 5$. 
The first topic is about participants' self test on immune level condition during the outbreak of COVID2019 , in which contains their habits, emotional problems, symptoms of low immunity, ways to enhance immune level. The second topic is about participants' outdoor activities rules during the outbreak of COVID-2019, in which contains outdoor activity frequency, outdoor activity time, outdoor activity content, outdoor activity places, participants' attitudes towards residential public space microclimate influence on outdoor activity. The third topic is about participants' satisfaction towards residential public space factors, in which contains overall satisfaction conditions and residential public space factors that needs to be changed most in the future.

\section{Results}

\subsection{Results of participants' self test on immune level condition}

The picture in the left side of Figure 4 shows participants' habits and customs. Lacking of exercise is the most popular options, and irregular work and rest is the second most one. There are $28.4 \%$ participants considering they have a relatively healthy conditions. At the same time, nearly $80 \%$ participants think cold climate will have significant influence on their immune level conditions, even their habits and customs. For example, they will eat more and prefer to stay at home rather than do outdoor activities in winter, as well as having a negative mood sometimes.
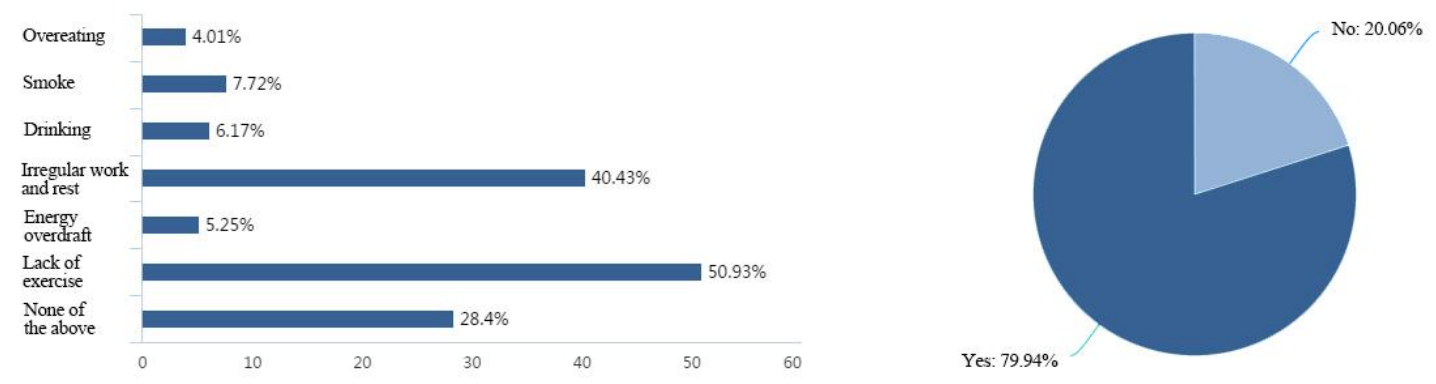

Figure 4: Participants' habits and attitude on cold climate influence

Figure 5 shows the statistics on the symptoms of hypo-immunity during home epidemic prevention. Some people show the symptom of low immune level. The most common symptom is insomnia, dreamy, easy to fatigue, which accounts for about $50 \%$. The second common symptom is listlessness, memory decline, in which there is $2 \%$ participants facing serious problems. Through the structured interview, some participants show these symptoms since the outbreak of COVID-2019, which is because they do not have plenty of time to go out for activity, especially they are easy to catch cold, and infectious diseases and can't be back to fitness in a short time.

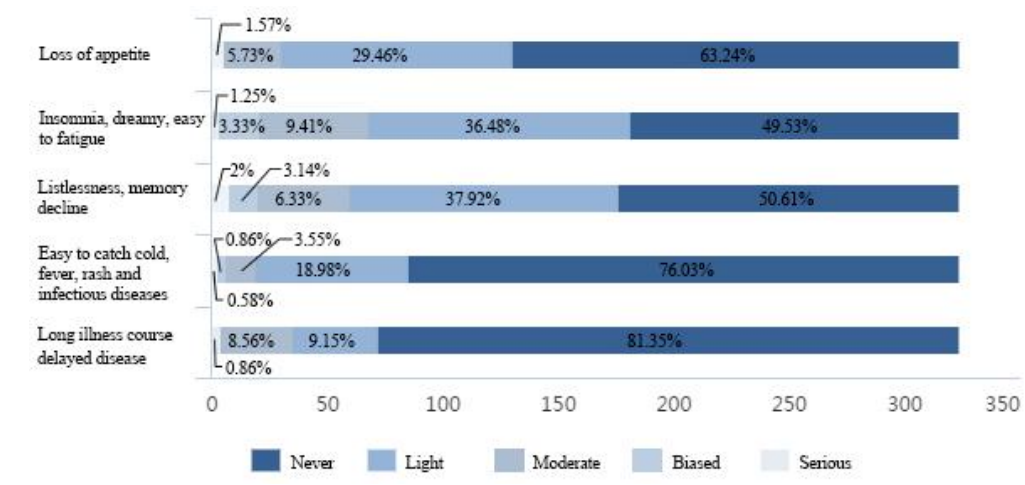

Figure 5: Statistics on the symptoms of hypo-immunity during home epidemic prevention 
Figure 6 shows the statistics on participants' attitude on changing living habits in order to improve immune level. When asked if they would change their diet and fitness habits in order to enhance the immune level, $83.64 \%$ participants think they will, nearly $8 \%$ participants said immune level is related to genetic factors and hard to change. About $10 \%$ participants said they do not have time to do fitness exercises, rather than unwilling to do them. The picture on the right side shows their attitude towards on how to improve the immune level. Strengthen physical exercise and develop good living habits are the most popular way. About $1.23 \%$ participants consider keeping a positive mood, vaccinate and reducing the chance of staying up late can also help to enhance the immune level.
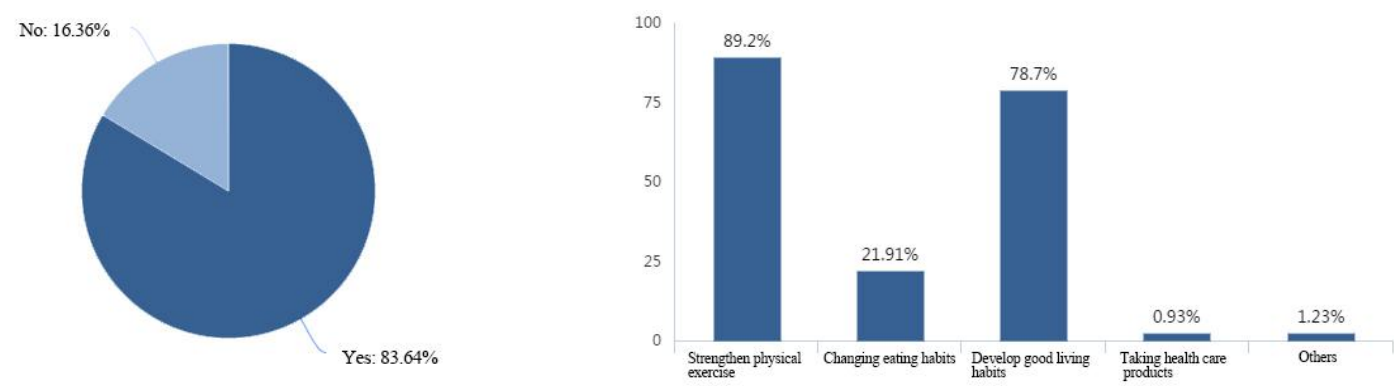

Figure 6: Statistics on participants' attitude on changing living habits in order to improve immune level

\subsection{Results of participants' outdoor activities}

In order to investigate the relationship between participants' immune level and outdoor activities, this paper collect the conditions of participants' outdoor activities. Figure 7 shows the outdoor activity frequency and time. Even though the field survey is developed during the outbreak of COVID-2019, there are still some participants keeping outdoor fitness exercises. As shown in the pictures, nearly $20 \%$ participants have outdoor activities everyday, $39.81 \%$ participants choose doing outdoor activity once a week or less, however some of them said they will do more at peace time, and also some participants consider cold climate have big influence on their outdoor activities. The most common time they spend on outdoor activities is $30-60$ minutes, $13.58 \%$ participants stay outside for more than one hour everyday. They said developing proper outdoor activities with necessary protective measures is beneficial for enhancing immunity.
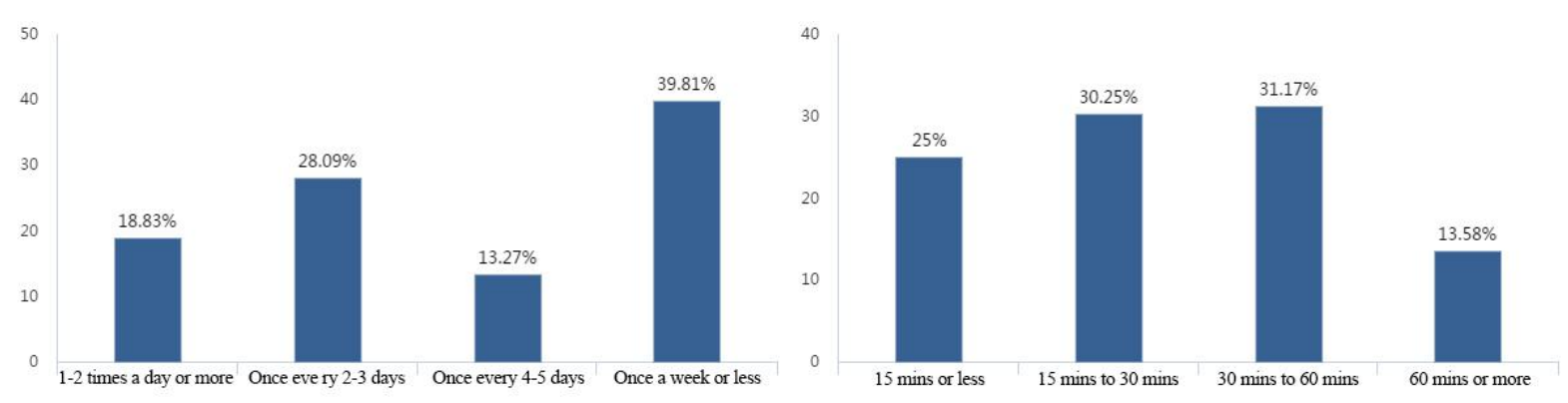

Figure 7: Outdoor activity frequency and time

Figure 8 shows the participants' outdoor activity content and it's effect for improving immune level. There are about $85 \%$ participants think doing outdoor activities has relationship with immunity, among which $27.78 \%$ participants think outdoor activity make great sense for enhancing immunity. Walking and buying necessitates are the main outdoor activity choices during the outbreak of COVID-2019, which account for $60.19 \%$ and $54.63 \%$ respectively. About $45 \%$ participants consider walking is the most effective way to relieve the discomfort of staying indoors for a long time, and they also think outdoor green plants can also bring people the feeling of relax and relieving bad mood. In addition, some participants said even though they do not have enough time to go for a walk, they still believe regular outdoor activity is extremely effective for improving people's immunity. 

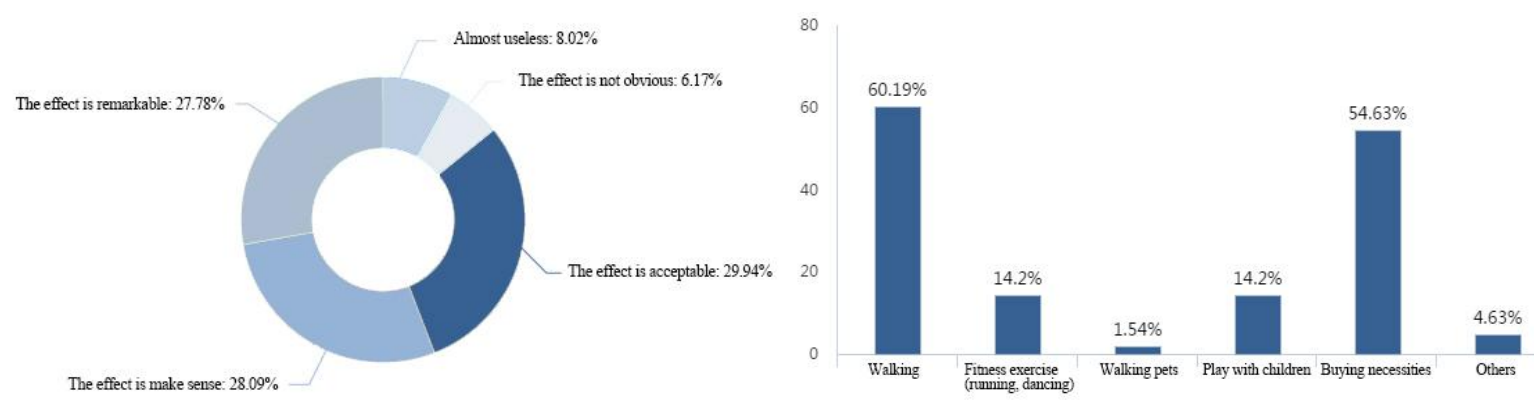

Figure 8: Outdoor activities' effect for improving immune level and the content in detail

\subsection{Results of participants' satisfaction on residential public space factors}

About $40 \%$ participants said they are not satisfied with the residential public space environment, which influences their outdoor activity behavior a lot. The number of participants who are unsatisfied in the old residential district is twice as that in the new residential district. Lacking of activity facilities and green landscape, as well as the noise are the main unsatisfactory aspects in the old residential district. In the new residential district, cold climate in winter is one of the most important factor which influence participants' satisfaction.

In order to tell the difference between immune level condition choices in various residential public space, the results of participants' satisfaction on the two residential public spaces is counted respectively. First, the paper discusses the relationship between participants' self test on immune level condition and satisfaction, the result is shown in Table 1. For old residential district, relatively healthy participants' preference on the environment is more than those people with low-immunity symptom. The correlation coefficients is 0.541 at level 0.01 . For new residential district, participants with high satisfaction usually have a better immune state.

Table 1: Correlation analysis of Participants' self test on immune level condition and satisfaction

\begin{tabular}{ccc}
\hline Residential district & Without low immune level/Satisfaction & With low immune level/Satisfaction \\
\hline Old residential district & $0.541^{* *}$ & 0.273 \\
New residential district & $0.472^{* *}$ & $-0.468^{*}$ \\
\hline
\end{tabular}

*-Significance at 0.05 level, **-Significance at 0.01 level

Second, the correlation analysis results between participants' outdoor activity behavior and satisfaction is shown in Table 2. It is can be seen than there is significant correlation between these two factors. For old residential district, all the outdoor activity behavior factors are related to satisfaction evaluation. The more satisfaction, the more frequent and prolonged outdoor activities. For new residential district, the correlation coefficients between participants' outdoor activity time and satisfaction is 0.681 at level 0.01 , and there is no correlation between frequency, content and satisfaction. It can be concluded that for residential district lacking of facilities and landscape, people's outdoor activities are more reply on their satisfaction.

Table 2: Correlation analysis of participants' outdoor activity behavior and satisfaction

\begin{tabular}{cccc}
\hline Residential district & Frequency/Satisfaction & Time/Satisfaction & Content/Satisfaction \\
\hline Old residential district & $0.325^{*}$ & $0.546^{* *}$ & $0.428^{* *}$ \\
New residential district & 0.386 & $0.681^{* *}$ & 0.575 \\
\hline
\end{tabular}

*-Significance at 0.05 level, **-Significance at 0.01 level 


\section{Discussion}

\subsection{Implications for urban planning and design}

Previous studies found that urban built environment has close relationship with urban development construction(Tsunetsugu, Y.etc.. 2013 \& Baton, J..etc..2016). In different countries and climate region, the correlation analysis results kinds are totally different. According to the analysis above, although there are influence of cold climate and epidemic situation, people still have the strong desire to outdoor activity. A considerable number of people believe outdoor activity is a key method to improve the immune level. The residential public space can promote people's physiological, psychological and social health effects by acting on people's perception and behavior. Thus, positive residential built environment is helpful to improving people's immune level through promoting people's outdoor activity in severe cold areas.

At the same time, participants' satisfaction on the residential public space is generally low, especially in the old residential district. Therefore, in the process of residential public space design, we should pay attention to the use of natural elements, physical environment and enough facilities, creating a positive space atmosphere, which is of great significance to improve the overall level of people's health and immune level.

For residential green space design, in order to optimize its ornamental function in winter, the proportion of evergreen coniferous trees such as Pinus sylvestris var, mongolica, and Pinus bungeanashould be increased (Yu, X.w. 2011). Meanwhile, in order to prolong the ornamental period of plants, trees with late fruit drop or early sprouting should be selected as far as possible. On the other hand, the selection of tree species with bright colors, such as redwood and Rosa multiflora, as well as the selection of tree species with beautiful tree shape, such as Mantou willow, weeping willow, and locust tree species, can make the winter green landscape of cities in severe cold regions colorful (Hu, H.M..etc. 2007).

For physical environment design, people will have a better feeling of thermal comfort under abundant sunshine conditions with the same wind velocity. For example, a Swedish study shows that under the same wind-sheltered condition, people's basic dividing line of thermal comfort temperature is $11^{\circ} \mathrm{C}$ under abundant sunshine, but $20{ }^{\circ} \mathrm{C}$ in the shadow. At the same time, people will have a high calcium intake and strong immune level through abundant sunshine according to Shi, X.S's study. To guarantee enough solar access in public urban spaces, surrounding building height and density design should be based on the solar altitude angle of the marginal season.

For service facilities design, the basic design goal is that people can do proper outdoor activities in four seasons. Besides some general service facilities in warm seasons, some ice and snow sports and facilities is also attractive to people in winter. In order to increase the comfort feeling to people, the facilities need to be bright colors and plastic or wood materials. In addition, some semi-indoor space with green plant landscape and leisure facilities need to be built for people to play and communicate with each other during the long winter, which can also meet the physiological and psychological needs of human being close to nature.

Even though these strategies are also suitable to cities in other climatic zone, it is much more meaningful for the cities in severe cold areas, which can attract more people to do out activity and keep a proper immune level especially in winter.

\subsection{Limitations of the study}

There are also some limitations in this study. Climate and outdoor environment factors are not the only, or even the most important criterion affecting public life in urban open public spaces in severe cold areas(Li, S.G.1994). People's immune level is more based on genetic factors, sleep, stress, diet, however, 
physical activity and emotional psychology also play an important role in the regulation of human immune level comfortable conditions(Long, Z.Z.1998 \& Katzschner, L.2006).

In further studies, the relationship between people's immune level, microclimate and residential public space factors in detail needs to be studied with more depth(Koohsari, J.,etc..2017), which need to be quantified and summarized. Through more precise calculation and simulation results, it is extremely useful to the cultivation of environmental urban policy and promoting the healthy city practice in severe cold areas.

\section{Conclusion}

Based on the field survey results, the study developed a preliminary analysis on people's self test on immune level condition and outdoor activity behavior during the outbreak of COVID-2019 in severe cold areas. It drew a conclusion that outdoor activities and residential public space factors have an great influence on people's immune level. As an important part in life, people have outdoor activities even during the epidemic and severe cold climate. In order to promote people's outdoor activities and immune level, there is great room for the improvement of residential public space, it provides planners and designers with useful strategies in residential public space planning and design projects in severe cold areas.

\section{Acknowledgment}

Chinese Postdoctoral Science Foundation (2020M670916)

National Natural Science Foundation of China (52008131)

\section{References}

Zhang, W.H. The only way to fight the virus is through the body's immune system, 17(2) [online] Available at: https://3g.163.com/news/article/F5J70J0904249CUG.html (Accessed: 17 February 2020).

Zimmer, K. Why some COVID-19 cases are worse than others, 24(2) [online] Available at: https://www.the-scientist.com/news-opinion/why-some-covid-19-cases-are-worse-than-others-67160 Accessed: 24 February 2020).

Lang, T.Y. Why do you have symptomatic infections? This is the truth, 22(2) [online] Available at: https://www.sohu.com/a/374919040_99931311 (Accessed: 22 February 2020).

Zhang, X.C. (1985 ) Conditional pathogen infection and anti infection immunity, Chinese Journal of Postgraduates of Medicine, 7: p32-33.

Maas, J.and Verheij, R.A.(2007) Are health benefits of physical activity in natural environments used in primary care by general practitioners in the Netherlands, Urban Forestry \& Urban Greening, 6(4): p227233.

Oh, B., Lee K.J.etc..Health and well-being benefits of spending time in forests: systematic review, Environmental Health and Preventive Medicine, 71(22): 351-360.

Yin, X.H, Jiang Z.F. and Yang X.L.(1996) Effect of cold on immune function of normal human body, Chinese Journal of Public Health,15(6): p370.

Du, C.Q.(2018) Effect of temperature variation on human thermal regulation and health and its molecular mechanism, a thesis submitted to Chongqing University. 
Wang, M, Jiang A.L.etc.. 'Temperature significant change COVID-19 transmission in 429 cities', Medrivix, 22(2)[online]. Available at: https://doi.org/10.1101/2020.02.22.20025791 (Accessed: 22 February 2020).

Zhong, N.S. http://news.sina.com.cn//2020-02-23/doc-iimxyqvz5160752.shtml

Leng, H. and Jiang C.Y. (2017) A field study on climate comfortable conditions of urban public open spaces in marginal season of winter cities, Open House International, 42: p28-35.

Shi, X.S. and Xu, C.Q. (2013) The large function of "small ion" - the mechanism of calcium ion regulating T cell antigen receptor activation, Chinese Journal of Cell Biology, 35(2): p115-18.

Wang, Z.G.(2003) Season and Health. Beijing: People's Medical Publishing House.

Thompson, C.W. (2007) Urban open space in the 21st century, Landscape and Urban Planning, 60(2): p5972.

Tsunetsugu, Y.,Lee, J.etc..(2013) Physiological and psychological effects of viewing urban forest landscapes assessed by multiple measurements, Landscape and Urban Planning, 113(3): p90-93.

Baton, J., Bragg, R.etc..(2016) Green exercise Linking nature health and well being. London: London Rutledge.

Yu, X.W. (2011) The research of urban green land for the northern winter - taking Beijing as an example, a thesis submitted to Beijing Forestry University. 11(1):50.

Hu, H.M., G, Y.L. (2007) Methods of enriching winter landscape in Northwest cities, Land Greening,

Li, S.G.(1994) User' behavior of small urban spaces in winter and marginal seasons, Architecture \& Behavior, 12(1): 95-109.

Long, Z.Z.(1998) Medical Immunology. Beijing: People's Medical Publishing House.

Katzschner, L..(2006) Behavior of people in open spaces in dependence of thermal comfort conditions, The 23rd conference on passive and low energy architecture, Geneva, Switzerland.

Koohsari, J., Badland, H., etc..(2017) Are public open space attributes associated with walking and depression? Cities.11(11): p408-415.

LI, Q., Morimoto, K.etc..(2008) A forest bathing trip increases human natural killer activity and expression of anti-cancer proteins in female subjects, Journal of Biological Regulators and Homeostatic Agents, 11(1):48-57. 